\title{
Study of copper nanoparticles formation on supports of different na- ture by UV-visible diffuse reflectance spectroscopy
}

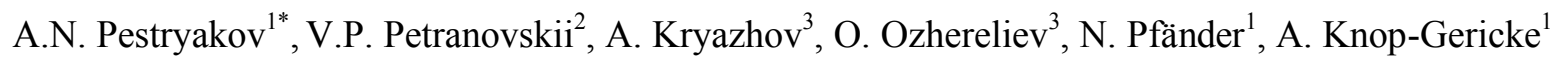 \\ ${ }^{1}$ Department of Inorganic Chemistry, Fritz-Haber-Institute of the MPG, Faradayweg 4-6, 14195 Berlin, Germany \\ ${ }^{2}$ Centro de Ciencias de la Materia Condensada, Ensenada B.C., 22800, México \\ ${ }^{3}$ Seversk Technological Institute, Seversk 634003, Russia
}

${ }^{*}$ Corresponding author: e-mail alex@,fhi-berlin.mpg.de, fax +49 3084134401

\begin{abstract}
Supported copper particles are widely used in heterogeneous catalysis. Influence of supports of different nature on the $\mathrm{Cu}$ particles formation is studied by the methods of UV-Visible spectroscopy of diffuse reflectance, XRD and electron microscopy. Different states of supported copper have been identified by UV-Vis spectroscopy: absorption bands at $250\left(\mathrm{Cu}^{+}\right), 320-370$ and $400-440$ (charge transfer bands of O-Cu-O and Cu-O-Cu complexes), 520-580 ( $\mathrm{Cu}_{\mathrm{n}}$ plasmon resonance) and 620-850 nm (d-d transitions in $\mathrm{Cu}^{2+}$ ions). The size of $\mathrm{Cu}$ clusters and $\mathrm{Cu}_{\mathrm{n}} / \mathrm{Cu}_{\mathrm{n}}{ }^{8+}$ ratio strongly depends on the support nature.
\end{abstract}

\section{Introduction}

Copper "supported on" or "incorporated into" solid matrices is widely used for preparation of catalysts and nanocomposites with unusual optical, electrical and magnetic properties [1-3]; those are generated by properties of clusters and nanoparticles. The nature of the support is one of the most relevant factors influencing the physicochemical characteristics of metal particles [4-9]. Our previous studies of the supported copper species revealed that under the action of acid-base nature of support the electronic and oxidation-reduction properties of the supported metal, its degree of dispersion, a surface diffusion, proton acidity and a number of other characteristics are considerably changed [1014]. All these factors exert a direct effect on formation of active surface of copper and, accordingly, on their catalytic properties.

The aim of the present work is the screening of the influence of supports of different nature on $\mathrm{Cu}$ particle formation by the methods of UV-Visible spectroscopy of diffuse reflectance.

\section{Experimental}

Crystalline $\mathrm{Cu}, 5 \mathrm{wt} \% \mathrm{Cu} /$ corundum and $1 \mathrm{wt} \%$ $\mathrm{Cu} /$ zeolite (zeolites are mordenites with variable ratio in the range $5<\mathrm{Si} / \mathrm{Al}<103$, erionite and clinoptilolite) samples were prepared for investigation of electronic states of supported $\mathrm{Cu}$ species. The metal was deposited by impregnation of the corundum support using $\mathrm{Cu}\left(\mathrm{NO}_{3}\right)_{2}$ solution, followed by calcination at $600^{\circ} \mathrm{C}$ for 4 hours. Cu-mordenites, $\mathrm{Cu}$ clinoptilolite and $\mathrm{Cu}$-erionite were prepared by ion exchange and reduced in hydrogen flow under fixed temperatures 150 , 250, 350 and $450{ }^{\circ} \mathrm{C}$. Crystalline $\mathrm{Cu}$ was prepared by electrolysis of $\mathrm{Cu}\left(\mathrm{NO}_{3}\right)_{2}$ solution. Crystalline $\mathrm{Cu}$ and $\mathrm{Cu}$ /corundum samples were applied to the processes of partial oxidation of methanol in a flow catalytic apparatus at $650^{\circ} \mathrm{C}$ for $76 \mathrm{~h}$; their UV-Vis spectra were taken before and after reaction run.

UV-visible spectra of diffuse reflectance (DRS) were measured by means of a CARY 300 SCAN and Shimadzu UV-300 spectrometers (supports were used as reference samples). Characterization by X-ray diffraction was carried out using a Philips X'Pert diffractometer with $\mathrm{CuK}_{\alpha}$ radiation. SEM characterization was carried out using JEOL 
JSM microscope, TEM micrographs were obtained on Philips CM 200 LaB6.

\section{Results and Discussion}

UV-visible spectra of fresh-prepared crystalline copper and $\mathrm{Cu} /$ corundum (Fig. 2) samples display only unstructured absorption corresponding to large metal particles. $\mathrm{XRD}$ and SEM show that the major part of copper in $5 \%$ wt. $\mathrm{Cu} /$ corundum sample is in the form of big particles ( $>$ $1000 \mathrm{~nm}$ ). These aggregates do not have specific signals in electronic spectra in accordance with the literary data. According to Refs [15-18] only highly dispersed copper particles possess discrete signals in UV-visible range. However, after the long-term catalyst run in the reactor the spectroscopic pattern of the catalysts was changed sufficiently. XRD and SEM measurements revealed that part of big particles of copper was aggregated into larger ones (> 3000-5000 $\mathrm{nm})$. However, $30-40 \%$ of the support surface was not covered by large aggregates, but contained metal in highly dispersed states (2-10 nm) (Fig. 1a,b). These copper nanoparticles display a number of characteristic signals in $\mathrm{UV}-\mathrm{V}$ is range. a

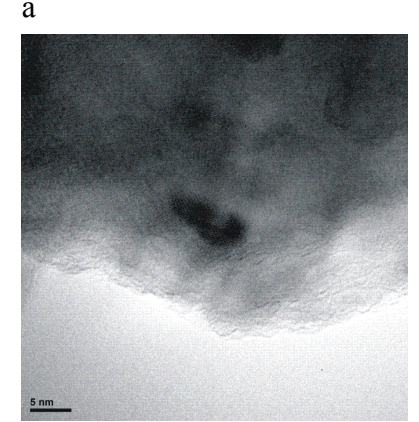

b

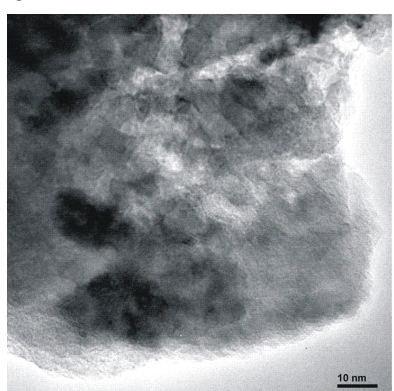

Fig. 1. TEM micrographs of the used $\mathrm{Cu} /$ corundum samples.

Thus, in the spectrum of the used $\mathrm{Cu} /$ corundum catalyst noticeable signals at 360, 430, $550 \mathrm{~nm}$ and wide absorption in 630-660 range are observed (Fig. 2). According to literary data [15-18] the first two signals belong to O-Cu-O (1) and $\mathrm{Cu}-\mathrm{O}-\mathrm{Cu}$ (2) complexes (charge transfer bands). Absorption at $620-660 \mathrm{~nm}(4)$ is attributed to electron d-d transitions in $\mathrm{Cu}^{2+}$ in distorted octahedral surrounding by oxygen in $\mathrm{CuO}$ particles. Absorption bands in the range of $520-540 \mathrm{~nm}$ some authors attribute to $\mathrm{CuAl}_{2} \mathrm{O}_{4}[15,17]$. However, formation of aluminate structures is not typical for corundum, so this signal can belong to plasmon resonance (3) of $\mathrm{Cu}_{\mathrm{n}}$ nanoparticles. This conclusion is confirmed by investigation of crystalline copper (Fig. 2) and $\mathrm{Cu} /$ zeolite samples (Fig. 3) as well as by calculations carried out in our previous work [19]. Thus, the prolonged run of the sample in catalytic reactor favors the formation of some amount of $\mathrm{Cu}^{2+}$ states and the metal nanoparticles.

The portion of dispersed copper particles increases if the support surface is modified by some metal oxides. Our previous studies of $\mathrm{Cu} / \gamma-\mathrm{Al}_{2} \mathrm{O}_{3}$ samples [12] showed that additives of $\mathrm{Zr}, \mathrm{Ce}$ and $\mathrm{La}$ oxides enhance metal-support interaction, since a large number of Lewis acid sites $\left(\mathrm{Ce}^{3+}\right.$,
$\mathrm{Ce}^{4+}, \mathrm{Zr}^{4+}, \mathrm{La}^{3+}$ ions) emerges on the support surface. This increases the dispersity of the metal particles and slows down the metal surface diffusion under thermal treatments. In the case of corundum this effect is not so pronounced because of low surface area of the support. However, in the spectra of $\mathrm{Cu} / \mathrm{ZrO}_{2} /$ corundum and $\mathrm{Cu} / \mathrm{CeO}_{2} /$ corundum samples the signals attributed to charged copper particles are more intensive (Fig. 2).

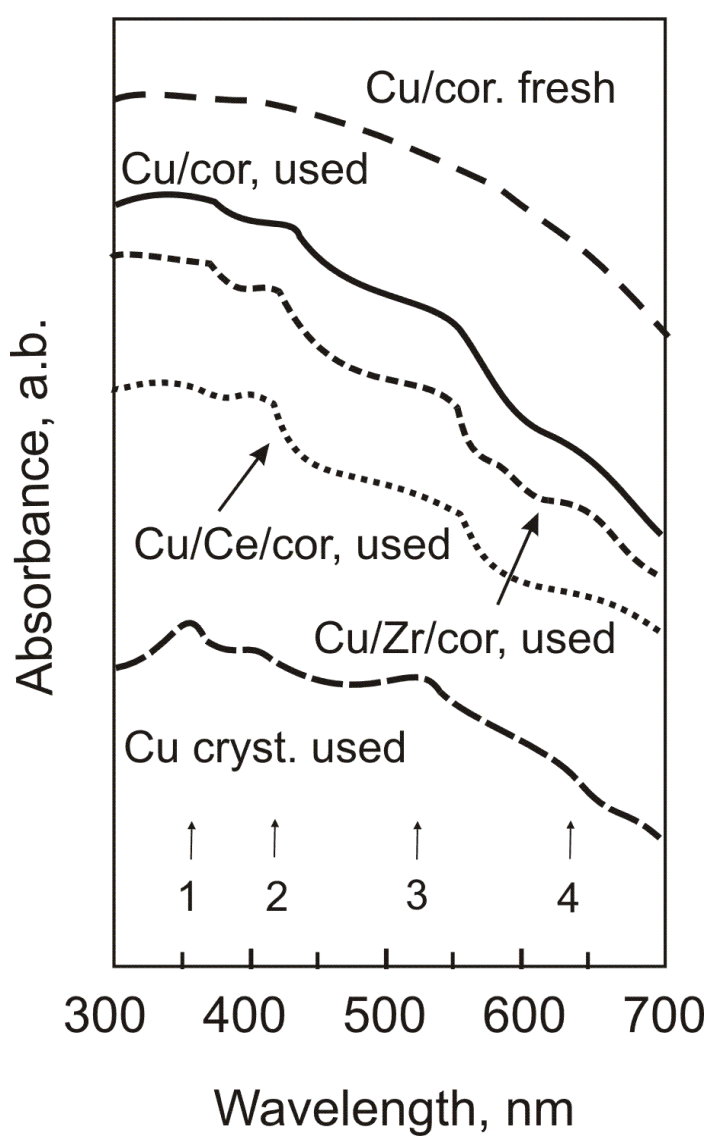

Fig. 2. DRS spectra of copper catalysts. Arrows mark positions of bands belonging to $\mathrm{Cu}-\mathrm{O}-\mathrm{Cu}(1), \mathrm{O}-\mathrm{Cu}-\mathrm{O}(2), \mathrm{Cu}_{\mathrm{n}}$ (3), $\mathrm{Cu}^{2+}(4)$.

Unexpected signals are observed in the spectra of exhaust crystalline copper catalyst, namely, two pronounced bands at $350 \mathrm{~nm}(1)(\mathrm{O}-\mathrm{Cu}-\mathrm{O})$ and $540 \mathrm{~nm}(3)\left(\mathrm{Cu}_{\mathrm{n}}\right.$ plasmon resonance) (Fig. 1). Bands at 420 (2) and $620 \mathrm{~nm}$ (4) are very weak. In this case we observe the formation of copper particles with separate electronic properties on the surface of bulk metal, because absorption bands in the range of 540-580 nm (3) belong to plasmon resonance bands of $\mathrm{Cu}_{\mathrm{n}}$ particles. Thus, catalytic reaction accompanied by oxidationreduction cycles of metal $\mathrm{Cu}$ favors the formation of small metal particles. For $\mathrm{Cu} /$ corundum it can be explain as $\mathrm{Cu}$ dispersion, but for crystalline copper appearance of plasmon resonance band can be only due to formation of nanoparticles with distinct electronic properties on the surface of bulk metal during the catalytic process. It is worthy of note that anodized electrodes developing surfaces with characteristic nano-roughness and active in SERS have fractal properties. 
This harsh surface forms so-called hot areas, in which the electromagnetic radiation concentrates; those are responsible for strengthening of an electromagnetic field and enhancing of Raman spectra [20]. This unusual at first glance process is also observed on the clean metal surfaces. In the nucleation of a new layer on a crystal, the properties of the small clusters formed initially on the surface play a significant role in the overall kinetics. When a Pt wire is evaporated in vacuum over Pt single crystal, Pt atoms arrive at the (111) plane and forms clusters of different size on the bulk Pt metal surface [21-22]. These platinum clusters on $\operatorname{Pt}(111)$ have been examined to provide atomistic information about their stability and mobility. It was shown from the STM experiments that dimers and all other small clusters are stable nuclei up to $400 \mathrm{~K}$, i.e. they do not dissociate on a time scale relevant to island formation. Detailed data were obtained also on the properties of Ir clusters containing from two to eight atoms stabilized on the Ir surface [23]. Similar mechanism can explain the development of catalytically active centers on the surface of bulk metals, but in this case it takes place in the atmosphere of reaction. So, not only small metal clusters and particles are formed, but their oxidized forms too.

In contrast with matrices like corundum and alumina, the crystallinity of zeolites a priori provides the special organization of the composite material due to highly regular porous system. Variation of zeolite structure, acidity of zeolites (regulated via $\mathrm{Si} / \mathrm{Al}$ ratio) and reduction temperature are the main factors influencing metal reducibility and appearance of copper reduced forms. In the recent publication [19] we have shown the leading role of $\mathrm{SiO}_{2} / \mathrm{Al}_{2} \mathrm{O}_{3}$ molar ratio (MR) in mordenite (from 10 through 206) on the optical appearance of reduced copper species. Changing the chemical composition of mordenite framework leads to a non-monotonous dependence of the copper reducibility upon MR (Fig. 3). Zeolite structure type is another factor to con-

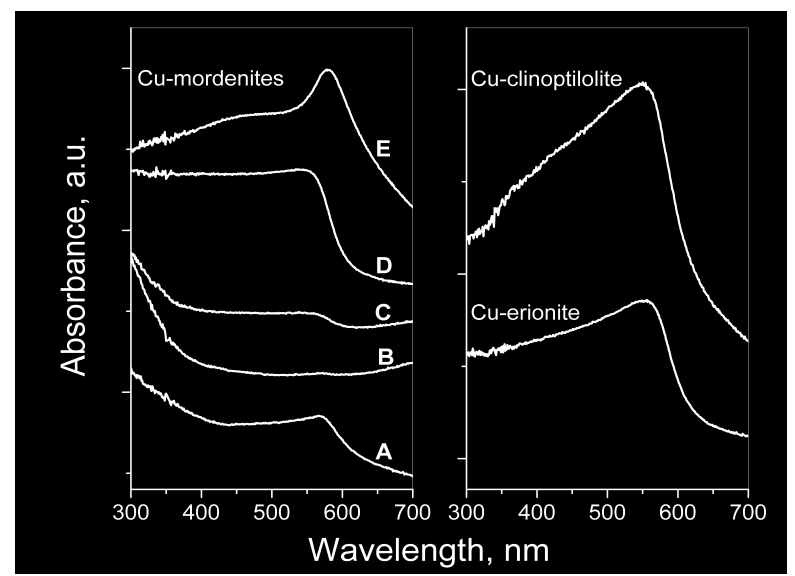

Fig. 3. DRS spectra of $\mathrm{Cu}$-zeolites reduced at $450{ }^{\circ} \mathrm{C}$. For $\mathrm{Cu}$-mordenites $\mathrm{SiO}_{2} / \mathrm{Al}_{2} \mathrm{O}_{3}$ molar ratios are: 10 (A), 15 (B), 20 (C), 31 (D) and 206 (E).

trol copper reducibility and state of final products. Properties of mordenites are controlled by MR from 10 through 206, while erionite and clinoptilolite were chosen as examples of the low-acidity matrices that are distinguished from mordenite by the geometry of intracrystalline voids and dielectric properties. It was shown earlier [4, 24-25] that coordination, localization and stabilization of copper ions in the zeolitic materials depend strongly on the structure and composition of zeolite matrix. The redox behavior of the system $\mathrm{Cu}^{2+} / \mathrm{Cu}^{+} / \mathrm{Cu}^{0}$ is known to be very sensitive to medium and complexation of copper by different ligands. For copper within zeolites this role is played by the solid matrix. DRS spectra of selected mordenite samples (Fig. 2) demonstrate that the same zeolite structure but with different MR change products of copper reduction drastically. Copper is easily reduced to small copper particles in mordenites with high $\mathrm{MR}=206$. According to estimations made by us recently from the spectral appearance [26], such shape of spectra has copper particles with size of order of several nanometers. Copper reduced under intermediate acidity of the matrix (mordenite with $\mathrm{SiO}_{2} / \mathrm{Al}_{2} \mathrm{O}_{3}=30$ ) reveals an optical absorption feature in the form of a shoulder associated with the particles of less size. High-acid mordenites with $\mathrm{SiO}_{2} / \mathrm{Al}_{2} \mathrm{O}_{3}=15$ prevent the particle formation (Fig. 3). The three types of zeolites under consideration $(\mathrm{Cu} /$ Mordenite, $\mathrm{Cu} /$ Erionite, and $\mathrm{Cu} / \mathrm{Clinoptilolite)} \mathrm{provide} \mathrm{similar} \mathrm{tempera-}$ ture range of the process (at $450^{\circ} \mathrm{C}$ the reduction can be considered as complete). But even at the beginning of reduction the shape of plasmon resonance peak is the same. It means that copper particles have approximately the same size as at the higher temperatures. That is to say, the size of particles is controlled by the matrix properties. Detailed calculations of the influence of these parameters upon the optical appearance of reduced copper were done in our previous studies [19,25].

\section{Conclusions}

1. Spectroscopic experiments identified different copper particles in the oxide matrices - ions, charged clusters, crystallites. These features depend strongly on the nature of the support.

2. Low-acid mordenites with highest $\mathrm{SiO}_{2} / \mathrm{Al}_{2} \mathrm{O}_{3}$ molar ratios, as well as clinoptilolite and erionite, favor efficient copper reduction with the formation of particles with an approximate radius of a few nanometers. This produces a pronounced plasmon resonance band in the visible range $(550-600 \mathrm{~nm})$.

3. During the catalytic process the portion of highly dispersed copper particles increases sufficiently as a result of surface diffusion of the metal. Modifying additives of metal oxides increases part of charged copper particles on the support surface. These effects are caused not only by the difference in the metal particle dispersivity, but also by interaction of copper atoms and ions with Lewis acid sites of the support. Copper ions, neutral and partly charged clusters $\left(\mathrm{Cu}_{\mathrm{n}}\right.$ and $\mathrm{Cu}_{\mathrm{n}}{ }^{\delta+}$ ) play a great role in formation of the catalyst active surface. 


\section{Acknowledgements}

The authors acknowledge funding for this research by CONACYT, Mexico, through grant No 32118-E; and RF President grant No 02-15-99360, Russia. Thanks are given to E. Flores, C. Gonzalez Sanchez and J.A. Peralta for the precious technical support.

\section{References}

1. Atomic clusters and nanoparticles, edited by C. Guet, P. Hobza, F. Spiegelman, F. David, NATO Advanced Study Institute, Les Houches, Session 73 (EDP Sciences, Springer-Verlag, 2001)

2. P. Jena, S.N. Khanna, B.K. Rao, J. Cluster Sci. 12, 443 (2001)

3. J. D. Aiken III and R. G. Finke, J. Mol. Catal. A:, 145 (1999) 1

4. P.T. Fanson, M.W. Stradt, J. Lauterbach, W.N. Delgass, Appl. Catal. B, 38 (2002) 331

5. J. Dedecek, O. Bortnovsky, A. Vondrov, B. Wichterlov, J. Catal. 200 (2001) 160

6. M.C. de Carvalho, F. B. Passos and M. Schmal, Appl. Catal. A, 193 (2000) 265.

7. B. Ganemi, E. Björnbom, B. Demirel, J. Paul, Micropor. Mesopor. Mater., 38 (2000) 287

8. F. Boccuzzi, S. Coluccia, G. Martra and N. Ravasio, J. Catal., 184 (1999) 316.

9. C. Torre-Abreu, C. Henriques, F. R. Ribeiro, G. Delahay and M. F. Ribeiro, Catal. Today, 54 (1999) 407

10. A.N. Pestryakov, V.V. Lunin, A.N. Devochkin, L.A. Petrov, N.E. Bogdanchikova, V.P. Petranovskii, Appl. Catal. A227 (2002) 125.

11. A.N. Pestryakov, A.A. Davydov, Appl. Surface Sci., 103 (1996) 479.

12. V.S. Gurin, V.P. Petranovskii, A.N. Pestryakov, A. Kryazhov, O. Ozhereliev, M.A. Hernandez, A.A. Alexeenko, European Physical J. D, 2003 , in press.

13. A.N. Pestryakov, V.V. Lunin, A.N. Devochkin, L.A. Petrov, N.E. Bogdanchikova, V.P. Petranovskii, Appl. Catal. A, 227 (2002) 125.

14. S.F. Tikhov, E.A. Paukshtis, V.A. Sadykov, Kinet. Catal. 30 (1989) 869.

15. O.V. Komova, A.V. Simakov, V.A. Rogov, D.I. Kochubei, G.V. Odegova, V.V. Kriventsov, E.A. Paukshtis, V.A. Ushakov, N.N. Sazonova, T.A. Nikoro, J. Mol. Catal. A, 161 (2000) 191.

16. V. Indovina, D. Pietrogiacomi and M.C. Campa, Appl. Catal. B, 39 (2002) 115

17. M.C. Marion, E. Garbovski, M. Primet, J. Chem. Soc. Faraday Trans., 86 (1990) 3027.

18. V.A. Markel, V.M. Shalaev, P. Zhang, W. Huynh L. Tay, T.L. Haslett, M. Moskovits, Phys. Rev. B59 (1999) 10903.

19. V. Petranovskii, V. Gurin, N. Bogdanchikova, A. Licea-Claverie, Y. Sugi, E. Stoyanov, Mat. Sci. Eng. A332 (2002) 174.

20. P.J. Feibelman, T. Michely, Surf. Sci. 492 (2001) L723.

21. K. Kyuno, G. Ehrlich, Surf. Sci., 437 (1999) 29.

22. S.C. Wang, G. Ehrlich. Surf. Sci. 239 (1990) 301.

23. J. Dedecek, B. Wichterlova, J. Phys. Chem. B101 (1997) 10233.

24. Y. Itho, S. Nishiyama, S. Tsuruya, M. Masai, J. Phys. Chem. 98 (1994) 960.

25. V. Petranovskii, V. Gurin, J.V.T. Flores, Proceeding of SPIE 4467 (2001) 377. 